\title{
Slow-Twitch Muscle Fiber
}

National Cancer Institute

\section{Source}

National Cancer Institute. Slow-Twitch Muscle Fiber. NCI Thesaurus. Code C12614.

A skeletal muscle fiber that utilizes aerobic respiration to fuel muscle contraction. Slow twitch muscle fibers, which have a high concentration of myoglobin and mitochondrial oxidative enzymes, are resistant to fatigue. 